\title{
Investigating the effects of physical and cognitive demands on the quality of performance under different pacing levels
}

\author{
S. Shaikh ${ }^{\mathrm{a} * 1}$, S. V. G. Cobb ${ }^{\mathrm{a}}$, D. Golightly ${ }^{\mathrm{a}}$, J. I. Segal ${ }^{\mathrm{b}}$ and C. M. Haslegrave ${ }^{\mathrm{a}}$ \\ ${ }^{a}$ Human Factors Research Group, Faculty of Engineering, University of Nottingham, Nottingham NG7 2RD, UK \\ ${ }^{b}$ Manufacturing Research Division, Faculty of Engineering, University of Nottingham, Nottingham NG7 2RD, UK
}

\begin{abstract}
The study was undertaken to investigate the effects of pacing on aspects of performance at an assembly task and on the operators' responses related to work behaviour, perceived workload and perceived stress. A particular objective of the study was to investigate whether physical and cognitive demands may interact in their influences on these effects. An assembly task was simulated in the laboratory and the level of pacing imposed, work height and memory load within the task were all varied. The results showed that the type of pacing commonly imposed (as is common with a lean manufacturing Takt time system in industry) can significantly affect both performance and perceived workload and stress. Physical demands (through work height affecting posture) and mental demand (through memory load) were also found to have significant effects, as would be expected from the many studies of these in the literature. More importantly, some interactions were found between pacing and work height in their effects on quality of assembly and the operator's own rating of performance, and between work height and memory load in their effects on errors. These findings will need to be taken into account by companies when implementing Takt time systems.
\end{abstract}

Keywords: takt time, work height, memory load, assembly work, performance

\section{Introduction}

In modern manufacturing, industrial assembly work has many pressures for speed, timeliness (working to deadlines) and quality. Lean manufacturing is one of the manufacturing methodologies that has proved very successful in improving productivity and quality [14]. It is a system of identifying sources of wastes and then reducing them by means of a set of lean tools and techniques. The Takt time system is a lean manufacturing tool that is widely used for controlling assembly work. It imposes a form of pacing on the assembly line (through a set target assembly completion time, which can vary according to the order book or customer demands). Takt time is defined as the maximum time allowed for producing a product in order to meet the customer demand [8]. Every stage and task in the production process is con- trolled by the Takt time specified. This Takt time is then broken down to give a maximum time for performing each task involved in the production of that product. The effect on the shop floor operators is to define the required pace of work. Lean manufacturing tends to lead to a short cycle, highly repetitive system.

Assembly work often involves concurrent performance of demanding physical and mental tasks. Features common to many assembly tasks include awkward postures, use of hands in manipulating components and tools, memorising defined procedures and component part numbers, rapid information processing and decision making, and control of task completion time by some form of pacing $[5,4,2]$. Some research studies have explored the independent impacts of physical or cognitive demands of Takt time on physical and cognitive stresses [9].

* Corresponding author. Email: epxsas4@nottingham.ac.uk; 
However, very few previous laboratory studies have examined whether there may be interactions between physical and cognitive demands [7].

Research literature has also shown some negative impacts of lean manufacturing for the shop floor activities, in terms of the risk of musculoskeletal disorders, lack of job control, intensified work, increased monotony, and difficulty in keeping pace [1].

So the present study was undertaken to investigate the effects of pacing (such as the imposition of Takt time) on aspects of task performance and on assembly workers' responses related to work behaviour, trade-off between speed and quality, perceived workload and perceived stress for an assembly task that demanded both physical and cognitive effort. The objective of the study was to investigate whether physical and cognitive demands may interact in their influences on these effects. The study was designed to capture performance measures (,including task quality, successful task completion and accuracy at the memory load element of the task) as well as subjective measures (including NASA TLX [10] and the stress and arousal checklist [3]).

\section{Method}

The experimental task was a simplified simulation of a task that had been observed in the automobile industry, which was performed at a workstation on a paced assembly line where the cycle time was controlled by a Takt time system. The cognitive element of the task was to read (from a computer display) and remember the code for the next automobile to arrive at the workstation, which happened at three minute intervals (the job having a Takt time of three minutes). The operator then walked to a shelf to pick the required part, identified by the code. The physical element of the task was to attach the part to the automobile.

\subsection{Participants}

Twelve participants ( 6 male and 6 female), between 23 and 50 years (mean 30.7, SD 7.3 years), were recruited for the laboratory experiment from the students and staff of the university. All participants were in good health and signed an informed consent form. The study was approved by the local ethical review committee of the university.

\subsection{Experimental design and procedure}

The physical aspect of the task in the laboratory simulated the assembly of components and consisted of attaching and tightening six wing nuts on threaded bolts. This was repeated for 12 cycles in each experimental condition. There were six assembly tasks in a row. Each condition was performed twice and number of correctly fastened nuts and bolts out of 72 assemblies was recorded in each condition. The task was performed while standing with the work height being at either elbow level or above shoulder level (as shown in Figure 1). The cognitive aspect of the task was to memorise the product code number (as presented on a computer screen) and to enter this number immediately before starting the assembly and then again after its completion. The code was generated randomly for each assembly.



Fig. 1 Assembly at above shoulder height

The task was performed under each of three pacing conditions (each on a separate day): with no pacing at the participant's preferred speed of work (control condition), at a low level of pacing with 90 seconds allowed for each assembly, and at a higher level of pacing with 60 seconds allowed for each assembly). Takt time at low pacing (90 seconds) and high pacing (60 seconds) was controlled by a computer beep signal.

The 12 conditions in Table 1 were performed by each participant over three days. Within each level of pacing the conditions were presented in random order. A practice session was provided to allow the participant to familiarize him/herself with the task. 
Each condition was then performed twice in order to reduce any practice effect.

Table 1 Independent variables

\begin{tabular}{lll}
\hline $\begin{array}{l}\text { Independent } \\
\text { variable }\end{array}$ & Level & \multicolumn{1}{c}{ Description } \\
\hline $\begin{array}{l}\text { Pacing } \\
\text { (by Takt time) }\end{array}$ & No pacing & $\begin{array}{l}\text { At own preferred } \\
\text { speed (No Takt time) }\end{array}$ \\
\cline { 2 - 3 } & Low pacing & Takt time 90 seconds \\
\cline { 2 - 3 } & High pacing & Takt time 60 seconds \\
\hline $\begin{array}{l}\text { Physical demand } \\
\text { (work height) }\end{array}$ & Elbow height & $\begin{array}{l}\text { Lower arm parallel to } \\
\text { ground }\end{array}$ \\
\cline { 2 - 3 } & $\begin{array}{l}\text { Above shoul- } \\
\text { der height }\end{array}$ & $\begin{array}{l}\text { Upper arm parallel to } \\
\text { ground }\end{array}$ \\
\hline $\begin{array}{l}\text { Cognitive demand } \\
\text { (memory load) }\end{array}$ & Low load & $\begin{array}{l}\text { Memorising } 4 \\
\text { code }\end{array}$ \\
\cline { 2 - 3 } & High load & $\begin{array}{l}\text { Memorising } \\
\text { code }\end{array}$ \\
\hline
\end{tabular}

\subsection{Measures}

Both objective and subjective measurements were made. The code responses typed by the participants and the time for each activity were recorded on computer. An observational record was made of the quality of tightening of nuts and bolts, numbers of dropped nuts and bolts, and numbers of fully completed assemblies.

Participants were also asked to provide a subjective assessment of their perceptions of the physical and mental workload. The assessment of the physical workload was obtained using a physical well-being checklist questionnaire (including a rating of fatigue) and a body part discomfort diagram. Raw NASA TLX data [3] was used to assess the subjective mental work load based on ratings on five subscales: mental demands, physical demands, temporal demands, performance and effort. A Stress and Arousal checklist was also used [2].

\subsection{Statistical analysis}

A paired comparison t-test was conducted to analyse the difference between the two repetitions of each condition. No significant effect was found and therefore the data was merged for further analysis. Analysis of variance (ANOVA) for repeated measures was used to test the effects of the three levels of pacing, two levels of work height and two levels of memory load on the perceived physical and mental stresses. The significance level was set at $\mathrm{p}<0.05$.

\section{Results}

\subsection{Objective measures}

A three way ANOVA was performed to find whether the effects of the three independent variables on time performing the assembly, time walking between different parts of the workstation, number of correct code responses, number of fully completed assemblies, and number of dropped nuts and bolts were significant. Table 2 shows the results.

\subsubsection{Performance time}

Significant effects were found for pacing $(\mathrm{F}=5.38$, $\mathrm{df}=2,22, \mathrm{p}<0.05)$ and work height $(\mathrm{F}=11.14$, $\mathrm{df}=$ $1,11, \mathrm{p}<0.05)$. Post hoc analysis showed that, as might be expected, performance time was significantly shorter at high pacing than at either no pacing or low pacing $(\mathrm{p}<0.05)$, but that there was no significant difference between the latter two. Performance time was longer for the high work height above shoulder level than for the elbow level work height. Mean (SE) of performance time for no pacing, low pacing and high pacing was 750 (27), 759 (32) and 673 (14) seconds respectively. Mean (SE) of performance time for elbow height and above shoulder height was 711 (21) and 743 (18) seconds respectively.

\subsubsection{Number of correct code responses}

No main effects (of pacing, work height or memory load) on the number of correct responses for the code memorised by the participant for each assembly were found to be significant. However, a significant interaction was found between work height and memory load $(\mathrm{F}=8.250, \mathrm{df}=1,11, \mathrm{p}<0.05)$. The number of correct code responses was greater at elbow height and low memory load as compared to the number of correct code responses at elbow height and high memory load. The mean (SE) numbers of correct code responses for the four conditions in the interaction effect were: at elbow height low memory load and high memory load were respectively $11.6(0.16)$ and $10.5(0.36)$ respectively, and at above shoulder height low memory load high memory load were respectively $11.30(0.21)$ and $10.9(0.21)$. 
Table 2

Results of analysis of variance for the objective measures

\begin{tabular}{|c|c|c|c|c|c|}
\hline \multirow[t]{2}{*}{ Independent variable } & \multicolumn{5}{|c|}{ Dependent variable } \\
\hline & Performance time & $\begin{array}{l}\text { Number of } \\
\text { correct code } \\
\text { responses }\end{array}$ & $\begin{array}{l}\text { Number of fully } \\
\text { completed assem- } \\
\text { blies }\end{array}$ & Walking time & $\begin{array}{l}\text { Number of dropped } \\
\text { nuts and bolts (out of } \\
72 \text { ) }\end{array}$ \\
\hline $\begin{array}{l}\text { Pacing } \\
\text { df }(2,22)\end{array}$ & $\begin{array}{l}F=5.38^{*} \\
L P \& N P>H P\end{array}$ & $\mathrm{~F}=2.23$ & $\begin{array}{l}F=18.30^{* *} \\
L P \& N P>H P\end{array}$ & $\begin{array}{l}F=8.801 * * \\
L P \& N P>H P\end{array}$ & $F=6.16$ \\
\hline $\begin{array}{l}\text { Work height } \\
\text { df }(1,11)\end{array}$ & $\begin{array}{l}\mathrm{F}=11.14 * * \\
\mathrm{ASH}>\mathrm{EH}\end{array}$ & $\mathrm{F}=0.80$ & $\mathrm{~F}=0.04$ & $\mathrm{~F}=2.55$ & $\begin{array}{l}\mathrm{F}=10.21 * * \\
\mathrm{ASH}>\mathrm{EH}\end{array}$ \\
\hline $\begin{array}{l}\text { Memory load } \\
\text { df }(1,11)\end{array}$ & $\mathrm{F}=0.98$ & $\mathrm{~F}=2.09$ & $\mathrm{~F}=0.40$ & $\mathrm{~F}=9.00$ & $\mathrm{~F}=0.01$ \\
\hline $\begin{array}{l}\text { Pacing X } \\
\text { Work height interac- } \\
\text { tion } \\
\text { df }(2,22)\end{array}$ & $\mathrm{F}=0.39$ & $\mathrm{~F}=0.89$ & $\begin{array}{l}\mathrm{F}=3.30 * \\
\mathrm{HP}+\mathrm{EH}>\mathrm{HP}+\mathrm{AS} \\
\mathrm{H}\end{array}$ & $\mathrm{F}=1.36$ & $\mathrm{~F}=0.37$ \\
\hline $\begin{array}{l}\text { Pacing X Memory } \\
\text { load interaction } \\
\text { df }(2,22)\end{array}$ & $\mathrm{F}=1.26$ & $\mathrm{~F}=0.22$ & $\mathrm{~F}=0.37$ & $\mathrm{~F}=4.15$ & $\mathrm{~F}=2.38$ \\
\hline $\begin{array}{l}\text { Work height } X \text { Mem- } \\
\text { ory load interaction } \\
\text { df }(1,11)\end{array}$ & $\mathrm{F}=0.20$ & $\begin{array}{l}\text { F=8.250* } \\
\text { EH+LM> } \\
\text { EH+HM }\end{array}$ & $\mathrm{F}=0.002$ & $\mathrm{~F}=0.54$ & $\mathrm{~F}=0.79$ \\
\hline $\begin{array}{l}\text { Pacing X Work height } \\
\text { X Memory load inter- } \\
\text { action } \\
\text { df }(2,22)\end{array}$ & $\mathrm{F}=0.13$ & $\mathrm{~F}=1.91$ & $\mathrm{~F}=0.96$ & $\mathrm{~F}=0.54$ & $\mathrm{~F}=0.30$ \\
\hline
\end{tabular}

\subsubsection{Number of fully completed assemblies}

The ANOVA showed pacing to have a significant effect $(\mathrm{F}=11.58, \mathrm{df}=2,22, \mathrm{p}<0.05)$ on the number of assemblies that were completed fully. Post hoc analysis showed that the difference was between high pacing and either no pacing or low pacing $(\mathrm{p}<0.05)$, but that there was no significant difference between no pacing and low pacing. Fewer assemblies were completed fully when the pacing was high. Mean (SE) of fully completed assemblies for no pacing, low pacing and high pacing was 72.0 $(0.00), 71.9(0.08)$ and $66.0(1.62)$ respectively.

\subsubsection{Walking time}

Walking time between assembly and the computer display was measured, as well as the time spent performing the assembly, to analyse any changes in behaviour in terms of partitioning time between the different parts of the task. The ANOVA showed that there was a significant effect of pacing $(\mathrm{F}=8.8, \mathrm{df}=$ $2,22, \mathrm{p}<0.05)$ on walking time. Post hoc analysis showed no difference between no pacing and low pacing. Participants moved faster under the high pacing condition than under the no or low pacing conditions. Mean (SE) of walking time for no pacing, low pacing and high pacing were 60.0 (2.4), 59.4 (2.0) and 53.1 (1.9) seconds respectively.

\subsubsection{Dropped nuts and bolts}

The ANOVA showed a significant effect of work height on the number of dropped nuts and bolts $(\mathrm{F}=$ $10.21, \mathrm{df}=1,11, \mathrm{p}<0.05)$ the number being higher at the above shoulder work height. Mean (SE) number of dropped nuts and bolts at elbow height and at 
above shoulder height was $1.8(0.27)$ and $2.4(0.41)$ respectively.

\subsection{Subjective measures}

Table 3 shows the summary of the analysis of variance for subjective measures.

Table 3

Results of analysis of variance for the subjective measures

\begin{tabular}{|c|c|c|c|c|c|c|c|c|}
\hline \multirow{3}{*}{$\begin{array}{l}\text { Independent } \\
\text { variable }\end{array}$} & \multicolumn{8}{|c|}{ Dependent variable } \\
\hline & \multicolumn{5}{|c|}{ NASA TLX } & $\begin{array}{l}\text { Physical } \\
\text { well- } \\
\text { being } \\
\text { checklist }\end{array}$ & \multicolumn{2}{|c|}{$\begin{array}{l}\text { Stress \& Arousal } \\
\text { scores }\end{array}$} \\
\hline & $\begin{array}{l}\text { Mental } \\
\text { demand }\end{array}$ & $\begin{array}{l}\text { Physical } \\
\text { demand }\end{array}$ & $\begin{array}{l}\text { Temporal } \\
\text { demand }\end{array}$ & Performance & Effort & Fatigue & Stress & Arousal \\
\hline $\begin{array}{l}\text { Pacing } \\
\text { df }(2,22)\end{array}$ & $\mathrm{F}=1.858$ & $\mathrm{~F}=2.34$ & $\begin{array}{l}F=19.04 * * \\
L P \& N P>H P\end{array}$ & $\begin{array}{l}F=8.02 * * \\
L P \& N P<H P\end{array}$ & $\begin{array}{l}F=7.00 * \\
H P>L P \& N P\end{array}$ & $\mathrm{~F}=0.42$ & $\mathrm{~F}=3.29$ & $\begin{array}{l}F=5.46 * \\
N P>L P \& \\
H P\end{array}$ \\
\hline $\begin{array}{l}\text { Work height } \\
\text { df }(1,11)\end{array}$ & $\begin{array}{l}\mathrm{F}=4.93 * \\
\mathrm{ASH}>\mathrm{EH}\end{array}$ & $\begin{array}{l}\mathbf{F}=27.26 * * \\
\mathrm{ASH}>\mathrm{EH}\end{array}$ & $\begin{array}{l}\mathbf{F}=19.66^{* *} \\
\mathrm{AS}>\mathrm{EH}\end{array}$ & $\mathrm{F}=3.17$ & $\begin{array}{l}\mathbf{F}=15.59 * * \\
\mathrm{ASH}>\mathbf{E H}\end{array}$ & $\mathrm{F}=4.35$ & $F=1.56$ & $\mathrm{~F}=0.10$ \\
\hline $\begin{array}{l}\text { Memory load } \\
\text { df }(1,11)\end{array}$ & $\begin{array}{l}F=8.97 * \\
\text { HM }>\text { LM }\end{array}$ & $\mathrm{F}=0.24$ & $\begin{array}{l}\mathrm{F}=5.04 * \\
\mathrm{HM}>\mathrm{LM}\end{array}$ & $\begin{array}{l}\mathrm{F}=4.88 * \\
\mathrm{LM}<\mathrm{HM}\end{array}$ & $\begin{array}{l}\mathrm{F}=5.45^{*} \\
\mathrm{HM}>\mathrm{LM}\end{array}$ & $\mathrm{F}=0.001$ & $\mathrm{~F}=0.40$ & $\mathrm{~F}=1.42$ \\
\hline $\begin{array}{l}\text { Pacing X } \\
\text { Work height } \\
\text { interaction } \\
\text { df }(2,22)\end{array}$ & $\mathrm{F}=0.91$ & $\mathrm{~F}=2.43$ & $\mathrm{~F}=0.40$ & $\begin{array}{l}\mathrm{F}=8.41 * * \\
\mathrm{LP}+\mathrm{EH}<\mathrm{LP} \\
+\mathrm{ASH} \dagger\end{array}$ & $\mathrm{F}=0.26$ & $\mathrm{~F}=0.17$ & $F=0.69$ & $\mathrm{~F}=0.08$ \\
\hline $\begin{array}{l}\text { Pacing X Memory } \\
\text { load interaction } \\
\text { df }(2,22)\end{array}$ & $\mathrm{F}=0.08$ & $\mathrm{~F}=0.29$ & $\mathrm{~F}=0.20$ & $\mathrm{~F}=2.50$ & $\mathrm{~F}=0.20$ & $\mathrm{~F}=0.21$ & $\mathrm{~F}=2.25$ & $\mathrm{~F}=1.82$ \\
\hline $\begin{array}{l}\text { Work height } X \\
\text { Memory load } \\
\text { interaction } \\
\text { df }(1,11)\end{array}$ & $\mathrm{F}=0.32$ & $\mathrm{~F}=1.32$ & $\mathrm{~F}=0.52$ & $\mathrm{~F}=0.36$ & $\mathrm{~F}=0.08$ & $\mathrm{~F}=1.92$ & $\mathrm{~F}=0.23$ & $\mathrm{~F}=1.46$ \\
\hline $\begin{array}{l}\text { Pacing X Work } \\
\text { height X Memory } \\
\text { load interaction } \\
\text { df }(2,22)\end{array}$ & $\mathrm{F}=1.25$ & $\mathrm{~F}=0.47$ & $\mathrm{~F}=0.17$ & $\mathrm{~F}=0.003$ & $\mathrm{~F}=1.28$ & $\mathrm{~F}=1.46$ & $\mathrm{~F}=0.35$ & $\mathrm{~F}=0.35$ \\
\hline $\begin{array}{l}* \mathrm{p}<0.05,{ }^{* *} \mathrm{p}<0.0 \\
\mathrm{NP}-\text { No pacing, LF } \\
\text { memory load } \\
\dagger \text { Note: This indica } \\
\text { scale is } 0 \text { - Perfect }\end{array}$ & $\begin{array}{l}\text { Low pacin } \\
\text { that the ra } \\
0 \text { - Failure }\end{array}$ & $\begin{array}{l}\text { High paci } \\
\text { performa }\end{array}$ & $\begin{array}{l}\text { ASH - Abov } \\
\text { at } \mathrm{LP}+\mathrm{ASH}\end{array}$ & $\begin{array}{l}\text { lder height, } \\
\text { se than that }\end{array}$ & $\begin{array}{l}\text { Elbow heigh } \\
\text { LP+EH becau }\end{array}$ & $\begin{array}{l}\text { M - Low } \\
\text { the NASA }\end{array}$ & mory lo & $\begin{array}{l}\text { HM - High } \\
\text { nance rating }\end{array}$ \\
\hline
\end{tabular}




\subsubsection{NASA TLX ratings}

Perceived work load, measured using the NASA TLX subscales. Main effects of pacing, work height or memory load were found to be significant for all five of the measures, as shown in Table 3, and there was one interaction effect between pacing and work height on the performance rating

\subsubsection{Fatigue rating}

No significant effects of pacing, work height or memory load (or of their interactions) were found for the fatigue rating.

\subsubsection{Stress and arousal scores}

No significant effects of pacing, work height or memory load (or of their interactions) were found for stress. However, ANOVA showed a significant effect of pacing $(\mathrm{F}=5.457, \mathrm{df}=2,22, \mathrm{p}<0.05)$ for arousal level. Post hoc analysis showed that the arousal level was higher with no pacing or high pacing than in low pacing conditions. Mean (SE) of arousal score for no pacing, low pacing and high pacing was 28.3 (1.06), $25.1(1.41)$ and $27.3(1.19)$ respectively.

\section{Discussion}

The study investigated the effects of pacing, work height and memory load on quality of performance and time spent on the different activities within the task cycle (specifically assembly and walking around the workstation). Subjective responses were also collected after each condition using NASA TLX to measure the work load, and the Stress and Arousal checklist to measure the stress and arousal levels, as well as a physical well being checklist to measure fatigue and discomfort.

As can be seen from the results in Tables 2 and 3, pacing, work height and memory demands all had an effect on some of the measures of performance and workload perceptions. The work height effects on performance and perceived physical demands and effort were those that would be expected from consideration of ergonomic workstation design.

The effects of memory load were also as was expected, specifically shown by the perceptions of mental demand, temporal demand, performance and effort. Memory load was not found to have an effect on any of the measures of performance, although this does not rule out a possible effect if greater memory load were demanded than the 6 digit and 8 digit recalls imposed in this experiment.

More interesting is the evidence of the complex ways in which the level of pacing can affect aspects of behaviour, such as the change in proportion of the cycle time spent on the assembly task in relation to the intervening times walking between different parts of the workstation or the quality of the work as measured by numbers of assemblies that were not fully (or adequately) completed. These changes in behaviour reflect the worker's decisions in making a trade-off between quality and speed of work and also show how pressure is felt by the need to maximise the time spent assembling at the expense of rushing the less productive parts of the task cycle (in this case walking). The subjective response measures also showed that pacing increased perceptions of mental demand, temporal demand, performance, effort and arousal. It should also be noted that the various effects were not simply due to pacing per se being imposed. The post hoc tests did not find a significant difference in any measure between the no pacing and the low pacing (90 s cycle time) conditions. It was the more rapid work rate imposed by the 60 seconds cycle time that affected both behaviour and participants' perceptions.

Also of considerable interest is the fact that interactions were found between organisational, physical and cognitive variables in their effects on some performance and subjective response measures, as shown by the three significant interactions highlighted in Tables 2 and 3. The fact that work height had a significant effect on perception of mental demand is also surprising and relevant. Further experiments will be necessary to understand these effects more clearly but the results do emphasise the need to consider the complex interplay between aspects of the task and the consequences of imposing pacing and deadlines on production line tasks while maintaining the quality of the work and the well-being of the workers.

When no pacing was imposed and the participants could perform the assemblies at their own speed, alll the assemblies were completed fully (finger tight) and the codes were memorised and typed accurately. Similar results were achieved at the lower pacing, which was set as 90 seconds to finish each assembly. The mean time of each assembly for no pacing and high pacing remained fairly constant across each condition [6]. The higher pacing, set as 60 seconds to finish each assembly, clearly caused more difficulty and some participants were unable to finish all their assemblies in the required time. The quality of performance also deteriorated, with increases in the 
number of poorly completed assemblies, errors, and numbers of dropped nuts and bolts. These results were similar to those found in studies conducted by Bosch, Dempsey et al. and Escorpizo and Moore $[2,6,9]$. The quality of performance was also affected by working at above shoulder height, which resulted in an increased number of drops [11]. The stress score was not affected significantly by pacing, work height or memory load, which is similar to the finding in a study by Poolton et al. [13].

\section{Conclusions}

It was thus found that the type of assembly line pacing commonly used (simulating the application of a Takt time system) can significantly affect aspects of both performance and perceived workload and stress. This has considerable implications for the design of Takt time systems in industry. Physical demands (through work height affecting posture) and mental demand (through memory load) were also found to have significant effects on performance and/or subjective measures, as would be expected from the many studies of these which have been reported in the literature. However, the possibility of interactions between organisational, physical and cognitive aspects of industrial assembly work has been little studied previously. So finding that such an interaction can occur is particularly interesting, as is the fact that it influenced the quality of the assembly work. This also will need to be considered carefully by companies when implementing Takt time systems.

\section{References}

[1] J. Angelis et al., The effects of lean production on worker job stress, International Journal of Operations \& Production Management, 2006, 26 (9-10), 1013-1038.
[2] T. Bosch et al., The effect of work pace on workload, motor variability and fatigue during simulated light assembly work, Ergonomics, 2011, 54 (2), 154-168.

[3] T. Cox, The nature and measurement of stress, Ergonomics, 1985, 28 (8), 1155-1163.

[4] R. Delbridge, J. Lowe, and N. Oliver, Shopfloor responsibilities under lean teamworking, Human Relations, 2000, 53 (11), 1459-1479.

[5] P.G. Dempsey and S.E. Mathiassen, On the evolution of task-based analysis of manual materials handling, and its applicability in contemporary ergonomics, Applied Ergonomics, 2006, 37 (1), 33-43.

[6] P.G. Dempsey et al., Influence of three principles of pacing on the temporal organisation of work during cyclic assembly and disassembly tasks, Ergonomics, 2010, 53 (11), 13471358.

[7] A. DiDomenico and M.A. Nussbaum, Interactive effects of physical and mental workload on subjective workload assessment, International Journal of Industrial Ergonomics, 2008, 38 (11-12), 977-983.

[8] R. Domingo et al., Redesigning an assembly line through lean manufacturing tools, International Journal of Advanced Manufacturing Technology, 2009, 43 (9-10), 949-958.

[9] R.S. Escorpizo and A.E. Moore, Quantifying precision and speed effects on muscle loading and rest in an occupational hand transfer task, International Journal of Industrial Ergonomics, 2007, 37 (1), 13-20.

[10] S. Hart and L. Stavenland, Development of NASA-TLX (Task Load Index): Results of empirical and theoretical research, Human Mental Workload, 1988, 139-183.

[11] L.H. Ikuma, M.A. Nussbaum, and K.L. Babski-Reeves, Reliability of physiological and subjective responses to physical and psychosocial exposures during a simulated manufacturing task, International Journal of Industrial Ergonomics, 2009, 39 (5), 813-820.

[12] W.F. Moroney et al., A comparison of 2 scoring procedures with the NASA Task Load Index in a simulated flight task, in: Proceedings of the IEEE 1992 National Aerospace and Electronics Conference - Naecon 1992, Vols 1-3, 1992, 734 740.

[13] J.M. Poolton et al., A comparison of evaluation, time pressure, and multi-tasking as stressors of psychomotor operative performance, Surgery, 2011, 149 (6), 776-782.

[14] P.T. Ward and R. Shah, Lean manufacturing: context, practice bundles, and performance, Journal of Operations Management, 2003, 21 (2), 129-149. 